\title{
Immunoproteasome deficiency leads to sustained pancreatic injury and delayed recovery from experimental pancreatitis.
}

Short title: Immunoproteasome controls acinar cell injury

Laura L. De Freitas Chama ${ }^{1}$, Frédéric Ebstein ${ }^{2}$, Birthe Wiesrecker ${ }^{1}$, Preshit R. Wagh ${ }^{1}$, Frank U. Weiss ${ }^{1}$, Heike Junker, Maja Studencka-Turski², Markus M. Lerch', Elke Krüger ${ }^{2}$, Matthias Sendler ${ }^{1}$

${ }^{1}$ Department of Medicine A, University Medicine Greifswald, Greifswald, Germany

${ }^{2}$ Institute of Medical Biochemistry and Molecular Biology, University Medicine Greifswald, Greifswald, Germany

Grant support: This work was supported by the Center of Excellence Mecklenburg-Vorpommern (ESF/14-BM-A55-0045/16).

Abbreviations used in this paper: ATF4, Activating transcription factor 4; BIP, binding immunoglobulin protein; BMDM, bone marrow derived macrophages, CCK, cholecystokinin, CD68 and CD206, cluster of differentiation 68 and 206; CHOP, C/EBP homologous protein; CXCL-10, C-X-C motif chemokine ligand 10; ER, endoplasmic reticulum stress; IFN, interferon; IL, interleukin; LC3, Microtubule-associated proteins 1A/1B light chain 3B; LMP2 and LMP7, Large multifunctional peptidase 2 and 7; Ly6G, Lymphocyte antigen 6 complex locus G6D; MECL-1, multicatalytic endopeptidase complex-like-1; MPO, myeloperoxidase; UPR, unfolded protein response; UPS, ubiquitin protein system; XBP1, X-box binding protein 1.

Address Correspondence to: Dr. Matthias Sendler, University Medicine Greifswald, Fleischmannstrasse 41. e-mail:matthias.sendler@uni-greifswald.de; Tel: + 4938348680486 ; Fax: + 493834867239 .

Conflict of Interest: The authors disclose no conflicts.

Preprint server: Biorxiv: doi: https://doi.org/10.1101/2020.11.17.386482

Word count: 3033

Author contributions Study concept and obtained funding: MML, EK and MS. Design of the study: LLFC, FE. Acquisition and analysis of data: LLFC, BW. Interpretation of data: LLFC, FE, BW, PRW, FUW, HJ, MST, MML, EK, MS. Drafting of the manuscript: LLFC. All authors provided critical revision of the manuscript for important intellectual content and approved the final version. 


\section{Abstract}

Background \& Aims: Uncovering potential new targets involved in pancreas recovery may permit the development of new therapies and improvement of pancreatitis treatment. One disease mechanism comprises the endoplasmic reticulum stress response and a key regulator to prevent proteotoxic stress in an inflammatory context is the immunoproteasome, an induced form of the constitutive proteasome. Our aim was therefore to investigate the role of the immunoproteasome in acute pancreatitis.

Methods: Acute pancreatitis was induced in wild type and LMP7 ${ }^{-/}$mice and several biochemical parameters for disease severity were addressed, including protease activities and histology of pancreatic damage. Realtime PCR was used to measure pro-inflammation and unfolded protein response. Serum IL-6 was detected by cytometric bead assay. Western blotting was used to quantify the ratio of ubiquitin-protein conjugates as well as unfolded protein response activation. Immunofluorescence identified leukocytes infiltration as well as ubiquitin-protein conjugates in the pancreas.

Results: In this study, we demonstrate that the $\beta 5 \mathrm{i} / \mathrm{LMP} 7$-subunit deletion correlates with persistent pancreatic damage. Interestingly, immunoproteasome-deficient mice unveil increased activity of pancreatic enzymes as well as higher secretion of Interleukin- 6 and transcript expression of the Interleukin IL-1 $\beta$, IFN- $\beta$ cytokines and the CXCL-10 chemokine. Thereafter, acinar cell death was increased, which appears to be due to the greater accumulation of ubiquitin-protein conjugates and prolonged unfolded protein response.

Conclusions: Our findings suggest that the immunoproteasome plays a protective role in acute pancreatitis via its role in the clearance of damaged proteins and the balance of ER-stress responses in pancreatic acini as well as in macrophages cytokine production.

Keywords: PSM8, inflammation, apoptosis, necrosis 


\section{Introduction}

Acute pancreatitis, one of the most common gastrointestinal diseases, is an inflammation of the pancreas, thought to be primarily due to premature intra-acinar activation of digestive pancreatic zymogens (1-2). Although most patients present with a mild form of the disease, about $20 \%$ develop severe pancreatitis associated with organ dysfunction, requiring intensive care (3-4). The global incidence of acute pancreatitis has been reported by Xiao et. al. (5) to be 34 cases per 100.000 per year. Autodigestion of the pancreas by its own proteases leads to acinar cell injury and subsequently to a local and systemic inflammatory response (6-7). Nevertheless, paradoxical results from trypsinogen deficient mice, which still developed experimental pancreatitis (8-9), has brought this traditional concept under review and suggest that the molecular mechanisms associated with the onset disease and progression are not fully understood. Many studies, specifically in animal models, have identified a variety of cellular events as being involved in the pathogenesis, such as premature activation of pancreatic enzymes (10), increase in calcium signaling (11-12), inflammatory cell infiltration (13-14), mitochondrial dysfunction (15) and endoplasmic reticulum stress (ER stress) (16-18).

Acini are the major source of digestive enzymes, thereby exhibiting the highest rate of protein synthesis and folding capacity with more abundant ER then all other cell types (19). ER stress is caused by accumulation of misfolded or unfolded proteins, which may arise during synthesis, folding and secretion of secretory and cell-surface proteins. Therefore, elucidating the molecular mechanisms of protein homeostasis may identify potential new targets of acinar cell injury. ER stress is counterbalanced by the unfolded protein response (UPR) machinery, which has a dedicated role in protein quality control and homeostasis (20). Impairment of UPR was found to be one cause of genetic varieties of pancreatic disorders (21-22). 
The ubiquitin proteasome system (UPS) plays an important role in intracellular protein degradation and turnover in eukaryotes via a multi-enzymatic machinery, entailing target protein ubiquitination and subsequent proteolysis by the $26 \mathrm{~S}$ proteasome (23). The immunoproteasome is an isoform of the constitutive proteasome (26S proteasome), which is assembled upon a triggering inflammatory response by Toll-like or cytokine receptor signaling, type I or type II interferons (IFNs), and TNF- $\alpha$ releases. It arises from the replacement of the $\beta$-catalytic subunits $\beta 1, \beta 2$ and $\beta 5$ in the $20 \mathrm{~S}$ standard proteasome core by i $\beta 1$ (large multifunctional peptidase 2, LMP2 encoded by PSMB9), i 32 (multicatalytic endopeptidase complex-like-1, MECL-1 encoded by PSMB10) and iß5 (LMP7 encoded by PSMB8), respectively, during de novo proteasome formation (24-25). Over the years the immunoproteasome has been recognized as an important player in shaping innate and adaptive immune responses by degradation of inflammatory mediators and improved MHC class I antigen presentation (26-27).

In addition to its roles in innate and adaptive immune cells, the immunoproteasome has also been linked to non-immune functions, namely cell differentiation and protein homeostasis, including intracellular protein clearance (28) and subsequently, may thus control of the ER stress levels. Likewise, a growing body of evidence has unveiled a consistent interdependence between ER stress imbalance and the immune system (2930). In view of the immunoproteasome role for protein clearance and ER-stress pathways, and the association of human mutations with autoinflammatory diseases (31), our aim was to investigate the role of the $\beta 5 \mathrm{i} / \mathrm{LMP} 7$ subunit in pancreatitis. We found that the immunoproteasome has a protective role in acute pancreatitis, since $\beta 5 \mathrm{i} / \mathrm{LMP} 7$ deletion increased disease severity and impeded recovery. Our work demonstrates that this proteasome isoform is involved in the clearance of ubiquitin-protein conjugates, attenuation of the pro-inflammatory response and UPR in pancreatitis. 


\section{Results}

\section{The $\beta 5 \mathrm{i} / \mathrm{LMP7}$ subunit is upregulated in acute pancreatitis}

First, we determined whether $\beta 5 \mathrm{i} / \mathrm{LMP7}$ subunit and its constitutive counterpart $\beta 5$ were expressed and differentially modulated in an in vitro model of pancreatitis using isolated acini. After supramaximal stimulation of the cells for $8 \mathrm{~h}$ and $24 \mathrm{~h}$ with the gastrointestinal hormone CCK, we assessed the protein levels of both subunits by western blotting. Pancreatic acini express basal levels of both subunits but only the $\beta 5 \mathrm{i} / \mathrm{LMP} 7$ subunit was upregulated after $24 \mathrm{~h}$ of treatment (Fig. 1A). In a next step we investigated whether the regulation of the $\beta 5 \mathrm{i} / \mathrm{LMP7}$ subunit would also be shifted in an in vivo mouse model of pancreatitis. We therefore used the caerulein model, which induces a mild and reversible form of the disease (33). Three experimental groups were designed: control (0h), acute phase (8h) and recovery phase (24h). Interestingly, the $\beta 5 \mathrm{i} / \mathrm{LMP} 7$ transcript levels were significantly increased at $8 \mathrm{~h}$ after the onset of pancreatitis. At $24 \mathrm{~h}$ its levels returned to baseline as measured in the control group (Fig. 1B). Importantly, no $\beta 5 \mathrm{i} /$ LMP7 transcripts were detected in the pancreas from $\beta 5 \mathrm{i} / \mathrm{LMP} 7^{-/-}$mice. Western blot analysis of pancreas homogenates showed an approximately threefold increase of $\beta 5 \mathrm{i} / \mathrm{LMP7}$ protein levels at $24 \mathrm{~h}$ compared to basal levels (Fig. 1C).

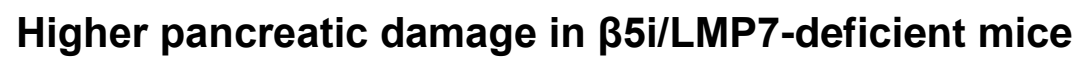

To investigate the role of the $\beta 5 \mathrm{i} / \mathrm{LMP} 7$ immunoproteasome subunit in pancreatitis, suggested by its up-regulation in vivo, disease severity was evaluated in $\beta 5 \mathrm{i} / \mathrm{LMP} 7^{-/-}$and wild-type littermate $\beta 5 \mathrm{i} / \mathrm{LMP}^{+/+}$mice. We performed the caerulein-induced pancreatitis model, including the same experimental groups as before. Biochemical markers of pancreatic injury (13), such as serum amylase and lipase activities, were increased by about $20 \%$ in $\beta 5 \mathrm{i} / \mathrm{LMP}^{-/-}$mice (Fig. 2A). Additionally, we measured trypsin and 
chymotrypsin activities in the pancreas homogenates of littermate and $\beta 5 \mathrm{i} / \mathrm{LMP} 7^{-/-}$mice. Trypsin and chymotrypsin consistently showed higher activities in the absence of B5i/LMP7 (Fig.2B). To examine early protease activation of living acini towards stimulation in the absence of $\beta 5 \mathrm{i} / \mathrm{LMP7}$, we performed an ex-vivo enzymatic assay (34). In the timecourse of $1 \mathrm{~h}$ CCK treatment, activities of trypsin and cathepsin B were similar in both genotypes, as well as the necrotic rate (Suppl. Fig.1). Thus, we showed that the lack of $\beta 5 \mathrm{i} /$ LMP7 did not alter the early protease activation within acini but during later pancreatitis progression.

Since intracellular protease activation is associated with acinar cell death (34), we next investigated whether apoptosis and necrosis were likewise increased in $\beta 5 \mathrm{i} / \mathrm{LMP} 7^{-/-}$mice. Apoptosis quantification was accomplished by labeling DNA fragmentation (Tunel assay) in paraffin-embedded pancreas. We observed that $\beta 5 \mathrm{i} / \mathrm{LMP} 7^{-/-}$mice exhibited a significantly higher number of Tunel-positive staining, approximately 1.5 fold higher at $8 \mathrm{~h}$, compared to littermate controls (Fig.2C). Histological pancreatic damage was further verified by hematoxylin and eosin staining (13), allowing us to identify and score necrotic areas and leukocytes infiltration. Pancreas from wild-type and $\beta 5 \mathrm{i} / \mathrm{LMP} 7^{-/}$mice exhibited equivalent pancreatic damage in the acute phase of the disease (8h). However, necrosis was increased at $24 \mathrm{~h}$ in $\beta 5 \mathrm{i} / \mathrm{LMP} 7-$ deficient mice and the tissue damage persisted for a longer period compared to the littermate group (Fig. 2D and E). To assess cell death, we performed serum lactate dehydrogenase activity assay, which was also increased by $20 \%$ in B5i/LMP7 $^{-/-}$mice at 8h (Fig.2D). Pancreatic injury was approximately two-fold higher in the absence of $\beta 5 \mathrm{i} / \mathrm{LMP} 7$ at the $24 \mathrm{~h}$ time point (Fig. $2 \mathrm{E}$ ), implying a role of the immunoproteasome in pancreas recovery after pancreatitis. Of note, increased inflammatory cell infiltration was detected in the absence of $\beta 5 \mathrm{i} /$ LMP7 (Fig. 2E), leading the next question to be addressed. 


\section{ß5i/LMP7 deficiency correlates with increased inflammation}

Our group has previously shown that acinar cell damage is linked to a pro-inflammatory state with increased infiltration of macrophages and neutrophils into the pancreas in response to cell injury (38). We therefore next characterized these leukocytes population by immunofluorescence in pancreatic tissue from all experimental groups. This approach was performed using specific antibodies for profiling of pro- and anti-inflammatory macrophages phenotypes (CD68 and CD206, respectively) and neutrophils (Ly6g). No significant difference was noticed in the count of infiltrating macrophages (Fig. 3A). However, a significant increase in neutrophil population was observed at 24h (Fig. 3B). Next, we measured the myeloperoxidase (MPO) activity in lungs, which is a peroxidase enzyme abundantly expressed in neutrophil granulocytes (39). As expected from the neutrophil infiltration in the absence of $\beta 5 \mathrm{i} / \mathrm{LMP} 7$, we also detected enhanced MPO activity (Fig.3B). We then quantified the activation of pro-inflammatory mediators in serum and in pancreas. Along with extended acinar cell injury we found that the transcription of proinflammatory cytokines IL-1 $\beta$, CXCL-10 at $8 \mathrm{~h}$ and IFN- $\beta$ at $24 \mathrm{~h}$ was increased in the absence of $\beta 5 \mathrm{i} /$ LMP7 compared to littermate controls by approximately 2.5 to 6 -fold (Fig. 3C). Likewise, serum levels of circulating IL-6 cytokine were elevated after $8 \mathrm{~h}$ of pancreatitis (Fig. 3D). To analyze whether the alterations in the pro-inflammatory cytokines regulation originated from pancreatic acini or macrophage BMDM cells, acinar cells were either stimulated with CCK alone or co-incubated with BMDM cells. This second approach allows the evaluation of macrophages activation in the onset of pancreatitis (38). In both cell types, we observed a higher regulation of IL-6 and IFN- $\beta$ cytokines in the absence of $\beta 5 \mathrm{i} / \mathrm{LMP} 7$. The $\mathrm{CXCL}-10$ chemokine was upregulated in pancreatic acini whereas IL-1 $\beta$ was significantly elevated in BMDM (Suppl. Fig.2). Taken 
together, our cytokine data indicate an increase in pro-inflammatory cytokines in acute pancreatitis in the absence of $\beta 5 \mathrm{i} / \mathrm{LMP} 7$ subunit.

\section{Impairment of ubiquitinated protein degradation in absence of $\beta 5 \mathrm{i} / \mathrm{LMP7}$}

In order to elucidate the molecular mechanisms associated with the disease phenotype of $\beta 5 \mathrm{i} / \mathrm{LMP7}^{-/-}$mice during pancreatitis, we examined the immunoproteasome function by immunofluorescence and western blotting; specifically, we analyzed the profile of ubiquitin-protein conjugates. First, we visualized the protein conjugates in the pancreas by immunofluorescence using an anti-ubiquitin antibody. Our data show an increased accumulation of ubiquitin-modified proteins at $8 \mathrm{~h}$ in the absence of $\beta 5 \mathrm{i} / \mathrm{LMP7}$, which was quantified by western blotting in insoluble fractions of pancreas homogenates from all experimental groups (Fig. 4A and B). These findings suggest that an impairment of immunoproteasome function has an impact on protein degradation and subsequent proteotoxic stress during pancreatitis.

Our next step was to determine whether the ubiquitin-protein conjugates were localized in pancreatic and/or immune cells by co-immunofluorescence experiments on pancreatic tissue. Strikingly, the conjugates were detected exclusively in acini but not in macrophages or neutrophils (Fig. 4C). In addition to the ubiquitin-dependent protein degradation pathway, we assessed whether the absence of $\beta 5 \mathrm{i} / \mathrm{LMP} 7$ also had an influence on autophagy. Autophagy dysregulation has been identified as one key mechanism involved in the pathogenesis of pancreatitis. LC3-II is the lipidated form of its cytosolic counterpart (LC3-I) and required for autophagosome formation. Sequentially, it engulfs cellular material for degradation and fuses with lysosomes, comprising the entity, in which protein cleavage occurs (40). Analysis of LC3-II protein levels showed similar 
activation in the absence of $\beta 5 \mathrm{i} / \mathrm{LMP} 7$, inferring that the induction of autophagy was not changed in our model (Suppl. Fig.3) and does not depend on the immunoproteasome.

\section{Sustained modulation of the unfolded protein response in $\beta 5 \mathrm{i} / \mathrm{LMP}{ }^{-/-}$mice}

The expected consequences of immunoproteasome impairment would be a delayed protein clearance (41). Thus we hypothesized that immunoproteasome-deficiency may result in increased endoplasmic reticulum stress and consequently, turn-on of the UPR signaling pathways. To address the UPR response, we performed quantitative real-time PCR in the pancreas to determine the expression of BIP and the transcription factors ATF4 and sXBP1, which are sensor and downstream targets of the UPR, respectively (Fig. 5A). LPM7 deficiency had no effect on the transcript regulation in the acute phase (8h) of the disease. Nevertheless, there was a prolonged induction of the transcripts at $24 \mathrm{~h}$ in the absence of $\beta 5 \mathrm{i} / \mathrm{LMP} 7$, with an up to twofold increase over littermate controls. In addition, protein levels of $\mathrm{C} / \mathrm{EBP}$ homologous protein (CHOP) (Fig.5B), which is a downstream target of the ATF4 and sXBP1 pathways, were significantly enhanced at $24 \mathrm{~h}$ in the pancreas of $\beta 5 \mathrm{i} / \mathrm{LMP} 7^{-/-}$mice, confirming the importance of a functional immunoproteasome in regulating UPR induction. Subsequently, the ER stress response was also investigated in in vitro experiments using pancreatic acini and co-culture of acini and BMDM (Fig. 5C and D). There was a clear induction of ER stress response transcripts BIP, ATF-4 and sXBP-1 in both cell types, but only acini underwent an altered regulation in the absence of $\beta 5 \mathrm{i} / \mathrm{LMP7}$.

Overall, our data imply that the immunoproteasome plays a protective role in acinar cell homeostasis, since elevated cell death was observed in the absence of $\beta 5 \mathrm{i} / \mathrm{LMP} 7$ in pancreatitis. The effect on pancreas recovery did not relate to changes in acinar cell regeneration, considering that the proliferation rate visualized by immunohistochemistry 
was not altered in the absence of $\beta 5 \mathrm{i} /$ LMP7 (Suppl. Fig.4). Therefore, the immunoproteasome appears to contribute to the clearance of ubiquitin-protein aggregates, resolution of inflammation and the reversal of UPR activation in pancreatitis.

\section{Discussion}

In this study we report a protective role of the immunoproteasome in pancreatitis and a beneficial effect on pancreatic injury resolution. The expression of the immunoproteasome subunits is known to be regulated not only in immune cells but also in non-immune cells, for example in pancreatic beta cells, muscle cells and adipocytes (42-44). Previous reports have demonstrated the importance of this proteasome isoform in cell differentiation and protein homeostasis $(41,45)$. Our work provides evidence for a role of the immunoproteasome in pancreatic acinar cell homeostasis and organ repair after cell injury. Notably, the $\beta 5 \mathrm{i} / \mathrm{LMP} 7$ subunit but not the $\beta 5$ constitutive subunit was up-regulated in an in vitro and an in vivo model of pancreatitis. Increased $\beta 5$ protein levels in acini from $\beta 5 i / L M P 7-d e f i c i e n t$ mice were observed as a compensatory mechanism, as seen before in other cell types (46-47). However, from the data obtained in this study, the immunoproteasome represents the major proteasome type involved in a rapid and efficient response to inflammation and ER stress during pancreatitis.

In the development of pancreatitis, well-known as a primarily sterile disease, two major players have been described in the past. Injured acinar cells release cellular components, for instance free ATP, histones or DNA, which act as damage-associated molecular patterns. These elicit the recruitment of macrophages and neutrophils into the pancreas, which then trigger inflammation and are associated with tissue injury (38). Beyond immune cells, acinar cells per se can undergo NF-kB transcription factor activation and secrete pro-inflammatory cytokines and chemokines, such as IL-6, TNF- $\alpha$ and MCP-1 
(48). On the other hand, several reports have associated $\beta 5 \mathrm{i} / L \mathrm{LMP} 7$ inhibition or deficiency with altered cytokine production (49-52). Here we show an opposite effect in which immunoproteasome deficiency correlates with an increased production of proinflammatory cytokines. In this context acini and macrophages were affected, considering that IL-1 $\beta$ is exclusively expressed by macrophages (14). Besides the differences detected in cytokine production, we also observed that immunoproteasome deficiency resulted in higher infiltration of neutrophils into the pancreas. Over the last decade, various studies have found an association between oxidative stress and acinar cell damage, with neutrophils as the central player in this process (53). The difference in neutrophil infiltration may possibly account for the stronger oxidative stress in the absence of $\beta 5 \mathrm{i} / \mathrm{LMP7}$. In line with this, Seifert et al. have previously shown a primordial role of the $\beta$ 5i/LMP7 subunit in preserving cell viability upon cytokine-induced oxidative stress (41).

The second aspect of our study highlights the effect of the immunoproteasome on acinar cell protein homeostasis. It is well established that acini, in response to supraphysiological secretagogue stimulation, develop ER stress and subsequently activate UPR (54). In turn, UPR upregulation has been recognized as a protective mechanism against acinar cell injury in pancreatitis (16). The UPR restores ER protein homeostasis through inhibition of protein synthesis, enhancement of protein folding and degradation mechanisms, such as autophagy and the UPS (20). Recently, the UPR and the immunoproteasome have appeared as pivotal networks in the maintenance of protein homeostasis and cell fate control (55-56). In our work, we show that the immunoproteasome is crucial for limiting UPR activation in isolated pancreatic acini. The UPR encircles stress response signaling pathways triggered by accumulation of misfolded or damaged proteins in the ER lumen (57). Although some studies did not report differences in the capacities of the constitutiveand the immunoproteasome to degrade ubiquitinated protein targets $(47,58)$, our work 
supports an essential role of the immunoproteasome in regulating this process and synchronizing UPR activation in pancreatitis. Unbalanced UPR, due to proteasome dysfunction has been implicated in the innate immune response, with the immunoproteasome playing a central role in the regulation of inflammation and UPR. The crosstalk between UPR and type I IFN signature has been proposed to evoke a sterile inflammation in the event of increased ER stress levels (59-62). Here, we also found B5i/LMP7 deficiency to be associated with an altered ER stress response and enhanced IFN and IFN-stimulated genes, such as IFN- $\beta$ and CXCL-10. We have previously shown that the IFN type I signaling pathway could be a promising target in the pancreatitis immune defense, using macrophages exposed to acini (14). Thus, our work reveals a functional link between IFN type I signaling and the UPR activation in pancreatitis, with the main effect on acinar cell protein homeostasis.

As a consequence of UPR dysregulation, represented by a prolonged time span for activation of sensor proteins and downstream targets, cell death appears to be the outcome (56). As verified by pancreas histology, immunoproteasome dysfunction correlated with sustained pancreatic damage, which was accompanied by increased acinar cell death, namely apoptosis and necrosis. These observations support previous findings, implying that the UPR is to a certain extent protective via restoring protein homeostasis. Nevertheless, its sustained activation may lead to cell death $(20,63)$. One of the proposed mechanisms involves the ATF4-CHOP signaling pathway, downstream targets of the PERK stress sensor. Our data align with previous information regarding the activation of this UPR pathway in acute pancreatitis (16). Beyond this we identified a role of immunoproteasome in preventing deleterious ER stress levels and maintaining acinar cell viability. 
Lastly, Zhu and coworkers have demonstrated beneficial effects of a proteasome inhibitor, named bortezomib, in two models of pancreatitis (64). In their work, significant differences in the histological score have been observed with the highest dose of bortezomib, which mitigated the disease severity through inhibition of acinar cell necrosis and suppression of NF-kB activity. The discrepancies to our $\beta 5 \mathrm{i} / \mathrm{LMP7}$ data are most likely due to the inhibition of all proteasome types by bortezomib.

In conclusion, the balance of ER stress levels and the maintenance of acinar protein homeostasis are important cellular processes in the resolution of tissue injury. In this context, the immunoproteasome appears to be a critical proteolytic complex in mitigating the pro-inflammatory response, preventing pancreatic injury and promoting subsequent recovery from pancreatitis. Future studies will be needed to identify pharmaceutically usable agents that improve or maintain the function of the immunoproteasome in order to translate this novel treatment target into a therapeutic modality. 


\section{Material and Methods}

\section{Animals}

Experiments were performed using male and female $\beta 5 \mathrm{i} / \mathrm{LMP} 7^{+/+}$(wild-type littermate) and $\beta 5 \mathrm{i} / \mathrm{LMP7}{ }^{-/-}$mice C57BL/6J strain background, generated as previously reported (32), weighing 20 to $25 \mathrm{~g}$ at about 2-3 months of age. Both genotypes were bred and maintained at the Greifswald University Animal Care Facility. Food and water were provided ad libitum to the animals, which were kept in a controlled environment with a constant 12:12-h lightdark cycle.

\section{Caerulein-induced acute pancreatitis model}

Acute pancreatitis was induced by eight hourly intraperitoneal injections of caerulein (50 $\mathrm{gg} / \mathrm{kg}$ bodyweight; cat: C9026-Sigma, Merck, Darmstadt, Germany), as previously described (33). The experimental protocol was approved by the institutional Animal Care and Use Committee. Three experimental groups were designed: control animals (Oh; no caerulein injections), $8 \mathrm{~h}$ corresponding to the acute phase of the disease and $24 \mathrm{~h}$ to the recovery phase. Five independent experiments were performed and no difference regarding sex was statistically significant. Serum and tissues were collected, processed and adequately stored to the experimental procedures, as described ahead.

\section{Biochemical assays}

Quantification of serum activities of amylase and lipase enzymes were assayed by photometric assays kits from Roche Hitachi (Grenzach-Wyhlen, Germany). Lactate dehydrogenase was measured in serum using a specific kit assay from Sigma (cat: MAK066, Merck). Pancreatic enzymatic activities, such as trypsin and chymotrypsin were determined in pancreatic tissue homogenates using fluorescent substrates as previously 
reported (34): Trypsin substrate (R110-(CBZ-Ile-Pro-Arg)2 was purchased from Life Technologies (Carlsbad, CA, USA); Chymotrypsin (Suc-AAPF-AMC) and Cathepsin B substrates (AMC-Arg2) were obtained from Bachem AG (Bubendorf, Switzerland). Myeloperoxidase (MPO) activity measurement in lung was performed as previously described (13). All activities from tissue homogenates were normalized suitably by protein concentration using Pierce BCA protein assay (cat: 23227, Thermo Fisher Scientific, Waltham, MA, USA).

\section{Measurement of pro-inflammatory cytokines}

The IL-6 pro-inflammatory cytokine was measured in serum and supernatant samples by fluorescence activated cell sorter (FACS) analysis using the CBA mouse inflammation kit, according the manufacturer's instructions (cat: 552364, Becton Dickinson, Heidelberg, Germany). IL-1 $\beta$ cytokine was measured in supernatant from macrophage culture using Peprotech kit assay (cat: 900-M47, Hamburg, Deutschland).

\section{Imaging analyses}

Histological pancreatic damage was verified by hematoxylin and eosin (H\&E) staining in paraffin-embedded pancreas ( $2 \mu \mathrm{m}$ sections) previously fixed in $4 \%$ formaldehyde. Paraffin embedded tissue was as well used for apoptosis analyses, using ApopTag® Red In Situ Detection Kit, following manufacturer's instructions (cat: S7165-Sigma; Merck, Darmstadt, Germany), and acinar cell proliferation by immunohistochemistry for the nuclear localization of Ki67 (rabbit polyclonal, cat: IHC-00375; Bethyl) (35). For the immunofluorescence experiments, we prepared frozen sections $(2 \mu \mathrm{m})$ of Tissue-Tek® O.C.T. compound-embedded pancreas, which guarantees fast freezing for optimal quality sectioning in a cryostat. The following primary antibodies were chosen: anti-FK2 (cat: BML-PW0150; Enzo life Sciences, Farmingdale, NY), anti-ubiquitin (cat: 43124, Cell 
Signaling Technology, Danvers, MA, USA), anti-CD68 (cat: ABIN181836, antibody online; Aachen, Germany), anti-Mrc1/CD206 (cat: OASA05048; Aviva Systems Biology, San Diego, CA), anti-Ly6g (cat: 25377, Abcam, Cambridge, MA). The secondary IgG antibodies (fluorophores Cy3 and Alexa488) were purchased from Jackson Immunoresearch (Pennsylvania, USA). The primary antibody dilution variated of 1:200 up to $1: 400$ with overnight incubation at $4^{\circ} \mathrm{C}$ and $1: 400$ for the secondary staining with $2 \mathrm{~h}$ incubation at room temperature. DAPI (4',6-diamidino-2-phenylindole; 1:1000) was used as nuclei staining and fluorescent mounting medium (DAKO) to cover the slides before imaging acquisition. Quantification of the CD68 and Ly6G immune staining was estimated manually from 5 random pictures in a magnification of 200 -fold from each animal. Total number of cells, through WEKA Segmentation in Image $\mathrm{J}$ software, was used to obtain the percentage of positive cells. The same design was applied to calculate apoptosis ratio.

\section{Isolation of acini}

Pancreas were carefully removed from wild-type C57BL/6J, $\beta 5 \mathrm{i} / \mathrm{LMP7^{+/+ }}$ (littermate) and $\beta 5 \mathrm{i} / \mathrm{LMP7^{-/ }}$ mice and digested with $1 \mathrm{mg}$ collagenase (Collagenase from Clostridium histolyticum; EC.3.4.24.3; SERVA Electrophoresis, Heidelberg, Germany), conditioned in Dulbecco's modified Eagle medium (DMEM; Thermo Fisher Scientific) with 2\% bovine serum albumin and 10mM HEPES, under sterile conditions, as initially described (36). Cell suspension was resuspended in fresh medium without collagenase and after 30 min of resting in water bath at $37^{\circ} \mathrm{C}$, three different approaches were addressed: 1) protease activation was examined in living cells upon an enzyme kinetic reaction up to $60 \mathrm{~min}$ with $1 \mu \mathrm{M}$ Cholecystokinin (CCK, fragment 26-33; C-2175 Sigma) stimulation whereas necrosis was measured by propidium iodide exclusion (37); 2) acini were directly platted in 12 well plates and incubated with $1 \mu \mathrm{M} \mathrm{CCK}$ for $6 \mathrm{~h}$ or $8 \mathrm{~h}$ and $24 \mathrm{~h}$ in a humidified atmosphere of $5 \% \mathrm{CO}_{2}$ at $37^{\circ} \mathrm{C}$, for subsequent total RNA or protein extraction; 3) or challenged with the 
same dose of CCK for 30min prior addition to the macrophage culture, as described below.

\section{Co-culture of acini and macrophages}

Femur of wild-type C57BL/6J, $\beta 5 \mathrm{i} / \mathrm{LMP}^{+/+}$(littermate) and $\beta 5 \mathrm{i} / \mathrm{LMP} 7^{-/-}$mice were collected under sterile conditions. Bone marrow stem cells were isolated by flushing the bone with sterile phosphate-buffered saline (PBS), plated and differentiated into macrophages (BMDM), as previously established (38). At the day of the experiment, BMDM culture received fresh medium, before being exposed to isolated acinar cells for 6 or 9 hours. Supernatant was collected for cytokine measurements and the cells were washed with PBS to withdraw non-adherent cells. Subsequently, cells were harvested with 5mM EDTA in PBS on ice and resulting pellet stored at $-80^{\circ} \mathrm{C}$ for posterior total RNA extraction.

\section{Transcript expression by quantitative Real-time PCR}

All reagents were purchased from Thermo Fisher Scientific, unless otherwise specified. Pancreas, acini and macrophages were collected and total RNA was extracted with Trizol reagent (cat: 15596026), as instructed by the manufacturer using RNAse-free labware. The RNA concentration was measured spectrophotometrically at $260 \mathrm{~nm}$. Next, oligo-dT and random hexamer primer $(\mathrm{RH}$; cat: SO181) were used to generate cDNA from 1-2 $\mu \mathrm{g}$ RNA using M-MLV reverse transcriptase (cat: 28025013). Reactions were performed in an Applied Biosystems QuantStudio 7 Flex Real Time System using SYBR Green PCR Master Mix (cat: 4334973), according to the manufacturer's recommendations. GAPDH or 5S ribosomal RNA expression was used as internal control, detailed primer sequences are shown in the table 1. 


\section{Measurement of protein levels by western blotting}

Protein extracts from pancreas homogenates and acini normalized for protein concentration (10 $\mathrm{\mu g}$ protein) were subjected to SDS-PAGE and then transferred onto PVDF (Polyvinylidene fluoride) or nitrocellulose membranes (Thermo Fisher Scientific) for immunoblotting. Specifically, insoluble ubiquitin-protein conjugates were detected after running $8 \%$ gels and PVDF membrane whereas $12 \%$ gels and nitrocellulose membrane were used for $\beta 5 \mathrm{i} / \mathrm{LMP} 7$ and CHOP and $15 \%$ for LC3-II analyses. Blocking was done with 1\% Roti-Block (cat: A151.1; Carl Roth, Karlsruhe, Germany) before primary antibody overnight incubation at $4^{\circ} \mathrm{C}$ at the following concentrations: anti-LMP7 (1:100000), anti- $\beta 5$ (1:2000; cat: 3330, Abcam), anti-ubiquitin (1:5000; FK2, BML-PW0150, Enzo Life Sciences), anti-CHOP (1:2000; 2895, Cell Signaling) and anti-LC3 $(1: 2000 ; 2775$, Cell Signaling). All membranes were incubated with secondary horseradish peroxidase conjugated antibody (1:10000; GE Healthcare, Chicago, Illinois, USA) for $1-2 \mathrm{~h}$ at room temperature. Afterwards, the membranes were developed by chemiluminescence with SuperSignal $^{\mathrm{TM}}$ West Femto-ECL-substrate (cat: 34095; Thermo Fisher Scientific) and imaging capture was acquired by Fusion equipment. Band intensities were quantified densitometrically using the Image $\mathrm{J}$ software (https://imagej.nih.gov/ij/) and normalized by loading control (amylase in case of acini and Ponceau staining for pancreas extracts).

\section{Statistical analyses}

Data are presented as means \pm SEM and the number of independent experiments is indicated. Statistical analyses, significant when $P<0.05$, were performed with GraphPad software (GraphPad, San Diego, CA) using one-way analyses of variance (ANOVA) followed by Turkey's multiple comparison test or unpaired Student's $t$-test, as appropriate. 
For the Suppl. Fig.1, SigmaPlot 11.0 (Systat Software, Erkrath, Germany) was used for the analyses.

\section{Acknowledgments}

We would like to thank Davide Figini for helping us with imaging analyses and Kathrin Gladrow for excellent technical assistance.

\section{References}

1. Hofbauer B, Saluja AK, Lerch MM, Bhagat L, Bhatia M, Lee HS, Frossard JL, Adler G, Steer ML. Intra-acinar cell activation of trypsinogen during caerulein-induced pancreatitis in rats. Am J Physiol. 1998;275(2):G352-62.

2. Halangk $W$ et al. Role of cathepsin $B$ in intracellular trypsinogen activation and the onset of acute pancreatitis. J Clin Invest. 2000;106(6):773-781. 
3. Hernández CA, Lerch MM. Sphincter stenosis and gallstone migration through the biliary tract. Lancet. 1993;341(8857):1371-3.

4. Hoffmeister A, Mayerle J, Beglinger C, Büchler MW, Bufler P, Dathe K, Fölsch UR, Friess H, Izbicki J, Kahl S, Klar E, Keller J, Knoefel WT, Layer P, Loehr M, Meier R, Riemann JF, Rünzi M, Schmid RM, Schreyer A, Tribl B, Werner J, Witt H, Mössner J, Lerch MM; members of the guideline committee. English language version of the S3consensus guidelines on chronic pancreatitis: Definition, etiology, diagnostic examinations, medical, endoscopic and surgical management of chronic pancreatitis. Z Gastroenterol. 2015;53(12):1447-95.

5. Xiao AY et al. Global incidence and mortality of pancreatic diseases: a systematic review, meta-analysis, and meta-regression of population-based cohort studies. Lancet Gastroenterol Hepatol. 2016;1(1):45-55.

6. Lerch MM, Saluja AK, Dawra R, Saluja M, Steer ML. The effect of chloroquine administration on two experimental models of acute pancreatitis. Gastroenterology. 1993;104(6):1768-79.

7. Leppkes M, Maueröder C, Hirth S, Nowecki S, Günther C, Billmeier U, Paulus S, Biermann M, Munoz LE, Hoffmann M, Wildner D, Croxford AL, Waisman A, Mowen K, Jenne DE, Krenn V, Mayerle J, Lerch MM, Schett G, Wirtz S, Neurath MF, Herrmann M, Becker C. Externalized decondensed neutrophil chromatin occludes pancreatic ducts and drives pancreatitis. Nat Commun. 2016;7:10973.

8. Dawra R et al. Intra-acinar trypsinogen activation mediates early stages of pancreatic injury but not inflammation in mice with acute pancreatitis. Gastroenterology. 2011;141(6):2210-2217.e2.

9. Halangk W, Krüger B, Ruthenbürger M, Stürzebecher J, Albrecht E, Lippert H, Lerch MM. Trypsin activity is not involved in premature, intrapancreatic trypsinogen activation. Am J Physiol Gastrointest Liver Physiol. 2002;282(2):G367-74.

10. Wartmann T, Mayerle J, Kähne T, Sahin-Tóth M, Ruthenbürger M, Matthias R, Kruse A, Reinheckel T, Peters C, Weiss FU, Sendler M, Lippert H, Schulz HU, Aghdassi A, Dummer A, Teller S, Halangk W, Lerch MM. Cathepsin L inactivates human trypsinogen, whereas cathepsin L-deletion reduces the severity of pancreatitis in mice.

Gastroenterology. 2010;138(2):726-37.

11. Krüger B, Albrecht E, Lerch MM. The role of intracellular calcium signaling in premature protease activation and the onset of pancreatitis. Am J Pathol. 2000;157(1):4350 .

12. Saluja AK, Dawra RK, Lerch MM, Steer ML. CCK-JMV-180, an analog of cholecystokinin, releases intracellular calcium from an inositol trisphosphate-independent pool in rat pancreatic acini. J Biol Chem. 1992;267(16):11202-7. 
13. Sendler $M$ et al. Tumour necrosis factor $\alpha$ secretion induces protease activation and acinar cell necrosis in acute experimental pancreatitis in mice. Gut. 2013;62(3):430-439.

14. Sendler M et al. NLRP3 Inflammasome Regulates Development of Systemic Inflammatory Response and Compensatory Anti-Inflammatory Response Syndromes in Mice With Acute Pancreatitis. Gastroenterology. 2020;158(1):253-269.e14.

15. Biczo G et al. Mitochondrial Dysfunction, Through Impaired Autophagy, Leads to Endoplasmic Reticulum Stress, Deregulated Lipid Metabolism, and Pancreatitis in Animal Models. Gastroenterology. 2018;154(3):689-703.

16. Barrera $\mathrm{K}$ et al. Acinar cell injury induced by inadequate unfolded protein response in acute pancreatitis. World J Gastrointest Pathophysiol. 2018;9(2):37-46.

17. Lukas $\mathrm{J}$ et al. Role of endoplasmic reticulum stress and protein misfolding in disorders of the liver and pancreas. Adv Med Sci. 2019;64(2):315-323.

18. Kereszturi E, Szmola R, Kukor Z, Simon P, Weiss FU, Lerch MM, Sahin-Tóth M. Hereditary pancreatitis caused by mutation-induced misfolding of human cationic trypsinogen: a novel disease mechanism. Hum Mutat. 2009;30(4):575-82.

19. Logsdon CD, Ji B. The role of protein synthesis and digestive enzymes in acinar cell injury. Nat Rev Gastroenterol Hepatol. 2013;10(6):362-370.

20. Lindholm D, Korhonen L, Eriksson O, Kõks S. Recent Insights into the Role of Unfolded Protein Response in ER Stress in Health and Disease. Front Cell Dev Biol. 2017;5:48.

21. Zenker M, Mayerle J, Lerch MM, Tagariello A, Zerres K, Durie PR, Beier M, Hülskamp G, Guzman C, Rehder H, Beemer FA, Hamel B, Vanlieferinghen P, Gershoni-Baruch R, Vieira MW, Dumic M, Auslender R, Gil-da-Silva-Lopes VL, Steinlicht S, Rauh M, Shalev SA, Thiel C, Ekici AB, Winterpacht A, Kwon YT, Varshavsky A, Reis A.Deficiency of UBR1, a ubiquitin ligase of the $\mathrm{N}$-end rule pathway, causes pancreatic dysfunction, malformations and mental retardation (Johanson-Blizzard syndrome). Nat Genet. $2005 ; 37(12): 1345-50$.

22. Fjeld K, Weiss FU, Lasher D, Rosendahl J, Chen JM, Johansson BB, Kirsten H, Ruffert C, Masson E, Steine SJ, Bugert P, Cnop M, Grützmann R, Mayerle J, Mössner J, Ringdal M, Schulz HU, Sendler M, Simon P, Sztromwasser P, Torsvik J, Scholz M, Tjora $E$, Férec C, Witt H, Lerch MM, Njølstad PR, Johansson S, Molven A. A recombined allele of the lipase gene CEL and its pseudogene CELP confers susceptibility to chronic pancreatitis. Nat Genet. 2015;47(5):518-522.

23. Kleiger G, Mayor T. Perilous journey: a tour of the ubiquitin-proteasome system. Trends Cell Biol. 2014;24(6):352-359.

24. Aki $\mathrm{M}$ et al. Interferon-gamma induces different subunit organizations and functional diversity of proteasomes. J Biochem. 1994;115(2):257-269. 
25. Griffin TA et al. Immunoproteasome assembly: cooperative incorporation of interferon gamma (IFN-gamma)-inducible subunits. J Exp Med. 1998;187(1):97-104.

26. Krüger E, Kloetzel PM. Immunoproteasomes at the interface of innate and adaptive immune responses: two faces of one enzyme. Curr Opin Immunol. 2012;24(1):77-83.

27. Kammerl IE, Meiners S. Proteasome function shapes innate and adaptive immune responses. Am J Physiol Lung Cell Mol Physiol. 2016;311(2):L328-L336.

28. Kimura H, Caturegli P, Takahashi M, Suzuki K. New Insights into the Function of the Immunoproteasome in Immune and Nonimmune Cells. J Immunol Res.

2015;2015:541984.

29. Ebstein $F$ et al. Immunoproteasomes are important for proteostasis in immune responses. Cell. 2013;152(5):935-937.

30. Longo $\mathrm{M}$ et al. Pathologic endoplasmic reticulum stress induced by glucotoxic insults inhibits adipocyte differentiation and induces an inflammatory phenotype. Biochim Biophys Acta. 2016;1863(6 Pt A):1146-1156.

31. McDermott A, Jacks J, Kessler M, Emanuel PD, Gao L. Proteasome-associated autoinflammatory syndromes: advances in pathogeneses, clinical presentations, diagnosis, and management. Int J Dermatol. 2015;54(2):121-9.

32. Fehling $\mathrm{HJ}$ et al. MHC class I expression in mice lacking the proteasome subunit LMP7. Science. 1994;265(5176):1234-1237.

33. Mayerle J, Schnekenburger J, Krüger B, Kellermann J, Ruthenbürger M, Weiss FU, Nalli A, Domschke W, Lerch MM. Extracellular cleavage of E-cadherin by leukocyte elastase during acute experimental pancreatitis in rats. Gastroenterology.

2005;129(4):1251-67.

34. Sendler M et al. Cathepsin B Activity Initiates Apoptosis via Digestive Protease Activation in Pancreatic Acinar Cells and Experimental Pancreatitis. J Biol Chem. 2016;291(28):14717-14731.

35. Murtaugh LC, Keefe MD. Regeneration and repair of the exocrine pancreas. Annu Rev Physiol. 2015;77:229-249.

36. Williams JA, Korc M, and Dormer RL. Action of secretagogues on a new preparation of functionally intact, isolated pancreatic acini. Am J Physiol Endocrinol Metab Gastrointest Physiol. 1978; 235: E517-E524.

37. Lerch MM, Lutz MP, Weidenbach H, Müller-Pillasch F, Gress TM, Leser J, Adler G. Dissociation and reassembly of adherens junctions during experimental acute pancreatitis. Gastroenterology. 1997;113(4):1355-66. 
38. Sendler M et al. Cathepsin B-Mediated Activation of Trypsinogen in Endocytosing Macrophages Increases Severity of Pancreatitis in Mice. Gastroenterology. 2018;154(3):704-718.e10.

39. Gukovskaya AS et al. Neutrophils and NADPH oxidase mediate intrapancreatic trypsin activation in murine experimental acute pancreatitis. Gastroenterology. 2002;122(4):974984.

40. Gukovskaya AS, Gukovsky I, Algül H, Habtezion A. Autophagy, Inflammation, and Immune Dysfunction in the Pathogenesis of Pancreatitis. Gastroenterology. 2017;153(5):1212-1226.

41. Seifert $U$ et al. Immunoproteasomes preserve protein homeostasis upon interferoninduced oxidative stress. Cell. 2010;142(4):613-624.

42. Freudenburg $W$ et al. Immunoproteasome Activation During Early Antiviral Response in Mouse Pancreatic $\beta$-cells: New Insights into Auto-antigen Generation in Type I Diabetes?. J Clin Cell Immunol. 2013;4(2):141.

43. Cui Z, Hwang SM, Gomes AV. Identification of the immunoproteasome as a novel regulator of skeletal muscle differentiation. Mol Cell Biol. 2014;34(1):96-109.

44. Kimura H et al. Immunoproteasome subunit LMP7 Deficiency Improves Obesity and Metabolic Disorders. Sci Rep. 2015;5:15883. Published 2015 Oct 30.

45. Johnston-Carey HK, Pomatto LC, Davies KJ. The Immunoproteasome in oxidative stress, aging, and disease. Crit Rev Biochem Mol Biol. 2015;51(4):268-281.

46. Kirschner F, Reppe K, Andresen N, Witzenrath M, Ebstein F, Kloetzel PM. Proteasome $\beta$ 5i Subunit Deficiency Affects Opsonin Synthesis and Aggravates Pneumococcal Pneumonia. PLoS One. 2016;11(4):e0153847.

47. Hewing B et al. Immunoproteasome subunit B5i/LMP7-deficiency in atherosclerosis. Sci Rep. 2017;7(1):13342.

48. Huang $\mathrm{H}$ et al. Activation of nuclear factor-KB in acinar cells increases the severity of pancreatitis in mice. Gastroenterology. 2013;144(1):202-210.

49. Muchamuel T et al. A selective inhibitor of the immunoproteasome subunit LMP7 blocks cytokine production and attenuates progression of experimental arthritis. Nat Med. 2009;15(7):781-787.

50. Liong S, Lim R, Nguyen-Ngo C, Barker G, Parkington HC, Lappas M. The immunoproteasome inhibitor ONX-0914 regulates inflammation and expression of contraction associated proteins in myometrium. Eur J Immunol. 2018;48(8):1350-1363.

51. Basler M, Dajee M, Moll C, Groettrup M, Kirk CJ. Prevention of experimental colitis by a selective inhibitor of the immunoproteasome. J Immunol. 2010;185(1):634-641. 
52. Wagner LK, Gilling KE, Schormann E, Kloetzel PM, Heppner FL, Krüger E, Prokop S. Immunoproteasome deficiency alters microglial cytokine response and improves cognitive deficits in Alzheimer's disease-like APPPS1 mice. Acta Neuropathol Commun.

2017;5(1):52.

53. Pérez S, Pereda J, Sabater L, Sastre J. Redox signaling in acute pancreatitis. Redox Biol. 2015;5:1-14.

54. Kubisch $\mathrm{CH}$, Logsdon CD. Secretagogues differentially activate endoplasmic reticulum stress responses in pancreatic acinar cells. Am J Physiol Gastrointest Liver Physiol. 2007;292(6):G1804-G1812.

55. Hetz C, Papa FR. The Unfolded Protein Response and Cell Fate Control. Mol Cell. 2018;69(2):169-181.

56. St-Pierre $\mathrm{C}$ et al. Immunoproteasomes Control the Homeostasis of Medullary Thymic Epithelial Cells by Alleviating Proteotoxic Stress. Cell Rep. 2017;21(9):2558-2570.

57. Hetz C, Chevet E, Oakes SA. Proteostasis control by the unfolded protein response [published correction appears in Nat Cell Biol. 2015 Aug;17(8):1088]. Nat Cell Biol. 2015;17(7):829-838.

58. Nathan JA, Spinnenhirn V, Schmidtke G, Basler M, Groettrup M, Goldberg AL. Immuno- and constitutive proteasomes do not differ in their abilities to degrade ubiquitinated proteins. Cell. 2013;152(5):1184-1194.

59. Ebstein F, Poli Harlowe MC, Studencka-Turski M, Krüger E. Contribution of the Unfolded Protein Response (UPR) to the Pathogenesis of Proteasome-Associated Autoinflammatory Syndromes (PRAAS). Front Immunol. 2019;10:2756.

60. Studencka-Turski M, Çetin G, Junker H, Ebstein F, Krüger E. Molecular Insight Into the IRE1a-Mediated Type I Interferon Response Induced by Proteasome Impairment in Myeloid Cells of the Brain. Front Immunol. 2019;10:2900.

61. Sotzny F, Schormann E, Kühlewindt I, Koch A, Brehm A, Goldbach-Mansky R, Gilling KE, Krüger E. TCF11/Nrf1-Mediated Induction of Proteasome Expression Prevents Cytotoxicity by Rotenone. Antioxid Redox Signal. 2016 Dec 1;25(16):870-885.

62. Poli MC, Ebstein F, Nicholas SK, de Guzman MM, Forbes LR, Chinn IK et al. Heterozygous Truncating Variants in POMP Escape Nonsense-Mediated Decay and Cause a Unique Immune Dysregulatory Syndrome. Am J Hum Genet. 2018;102(6):11261142.

63.Sano R, Reed JC. ER stress-induced cell death mechanisms. Biochim Biophys Acta. 2013;1833(12):3460-3470.

64. Zhu Q et al. Dynamic changes of proteasome and protective effect of bortezomib, a proteasome inhibitor, in mice with acute pancreatitis. Biochem Biophys Res Commun. 2018;505(1):126-133. 


\section{Figure Legends}

Figure 1: Expression and regulation of LMP7 subunit in isolated acini and in experimental acute pancreatitis. A) Isolated acini were treated with $1 \mu \mathrm{M}$ of CCK for $8 \mathrm{~h}$ and $24 \mathrm{~h}$. The levels of LMP7 and $\beta 5$ subunits were determined by western blotting. Amylase was used as an internal control and a ratio of LMP7 was calculated. B) Transcript levels of LMP7 were evaluated by real-time PCR in the pancreas after caerulein-induced pancreatitis. 5S was used as an internal control $(n=5-8)$. C) Western blotting analyses of LMP7 subunit in the pancreas during pancreatitis $(n=9-10)$; Data from independent experiments are expressed as means \pm SEM. ${ }^{*} p<0.05,{ }^{\star *} p<0.01,{ }^{* *} p<0.001$.

Figure 2: Higher pancreatic damage in the absence of LMP7. A) Serum amylase, lipase and D) lactate dehydrogenase activities were measured using specific chromogenic substrates. All enzymes are significantly more active after $8 \mathrm{~h}$ of pancreatitis in $\mathrm{LMP7}^{-T-}$ compared to $\mathrm{LMP7}^{+/+}$group. Oh $(\mathrm{n}=10-13) ; 8 \mathrm{~h}$ and $24 \mathrm{~h}(\mathrm{n}=20-25)$. B) Trypsin and chymotrypsin activities were quantified in the pancreas using corresponding fluorescent substrates. Trypsin and chymotrypsin activities are stronger regulated in the absence of LMP7 at 24h group. Oh ( $n=3-4), 8 \mathrm{~h}(n=8-13)$ and $24 \mathrm{~h}(\mathrm{n}=5-9)$. C) Apoptotic bodies were detected by tunel DNA fragmentation assay in paraffin-embedded pancreas and DAPI was used as nuclei staining $(n=4-6)$. Apoptosis ratio was computed based on positive versus total number of cells, normalized by the corresponding LMP7 $7^{+/+} 8 \mathrm{~h}$ group. D) Histology of pancreatic damage was visualized by hematoxylin \& eosin staining of pancreas. The immune infiltrating cells correlates with the extension of necrotic areas and subsequent decrease of unaffected healthy exocrine pancreas. E) Histoscore of disease severity, including necrosis and infiltration. No significant differences were observed after $8 \mathrm{~h}$ of pancreatitis, nonetheless the pancreas from LMP7 $7^{-/}$mice presented with higher cell damage compared to the littermate group at $24 \mathrm{~h}$. Image representative of five independent experiments. Scale bars, $50 \mu \mathrm{m}$. Size of experimental groups: $0 \mathrm{~h}(\mathrm{n}=9-10) ; 8 \mathrm{~h}$ and $24 \mathrm{~h}(\mathrm{n}=14-17)$. Data obtained from five independent experiments are expressed as means \pm SEM. ${ }^{*} p<0.05,{ }^{* *} p<0.01,{ }^{* * *} p<0.001$.

Figure 3: Increased inflammation in the absence of LMP7. A) and B) Immunofluorescence in frozen pancreas sections was performed using macrophages (CD68; A) and neutrophil (LY6G; B) markers antibodies. Quantification of positive cells for each leukocyte population was calculated based on the total number of cells, visualized by DAPI nuclei staining (CD206 data not shown). $0 \mathrm{~h}(\mathrm{n}=3-4)$, 8h and $24 \mathrm{~h}(\mathrm{n}=8-9)$. B) Enhanced neutrophil infiltration in LMP7 ${ }^{-/}$mice is also reinforced by MPO activity in lung. Oh ( $n=12-13)$, 8h ( $n=19-23)$ and 24h ( $n=6-9)$. C) Transcripts levels of IL-1 $\beta, C X C L-10$ and IFN- $\beta$ genes are significantly stronger regulated in the absence of LMP7, which were determined by real-time PCR using specific primers with $5 \mathrm{~S}$ as housekeeping. LMP7 $7^{+/+}$ groups- $0 h(n=4-5)$, 8h and 24h ( $n=4-7)$; LMP7 $7^{-/}$groups- $0 h(n=4), 8 h(n=10-13)$ and $24 h$ $(\mathrm{n}=4-9)$. D) Interleukin-6 levels were measured in serum. Data were normalized to the values of the $8 \mathrm{~h} \mathrm{LMP7} 7^{+/}$group. Oh $(n=10-13) ; 8 \mathrm{~h}$ and $24 \mathrm{~h}(\mathrm{n}=20-25)$. Scale bars, $20 \mu \mathrm{m}$. Data are representative of five independent experiments and expressed as means \pm SEM. ${ }^{*} p<0.05,{ }^{* *} p<0.01$.

Figure 4: Impairment of ubiquitinated protein degradation in the pancreatic acini from $\mathrm{LMPT}^{-/-}$mice. Immunofluorescence in pancreas sections performed using ubiquitin A) alone or C) combined with either CD68, Ly6G or trypsin antibodies. The co-localisation 
of ubiquitin was exclusively visualized with trypsin antibody, DAPI was used as nuclei staining. Scale bars, $20 \mu \mathrm{m}$. Image representative of five independent experiments. B) Higher accumulation of insoluble ubiquitin conjugates was also visualized by western blotting and its ratio to a loading control (ponceau staining) was estimated by densitometry. $(n=8-12)$. Data are representative of independent experiments and expressed as means \pm SEM. * $\mathrm{p}<0.05$.

Figure 5: Stronger induction of ER stress transcripts in acute pancreatitis and isolated acini from LMP $7^{-/-}$mice. ER stress transcripts levels of BIP, ATF4 and sXBP-1 were determined by real-time qPCR using specific primers and $5 \mathrm{~S}$ or GAPDH as housekeeping. A) RNA total from pancreas after pancreatitis; $\operatorname{LMP7}^{+/+}(\mathrm{n}=10-13)$ and LMP7 $^{-/-}$groups $(n=10-21)$. B) CHOP protein expression was assessed by western blotting in the pancreas $(n=9-12)$. C) Isolated pancreatic acini stimulated with $1 \mu \mathrm{M}$ of CCK for $6 \mathrm{~h}$ $(n=3)$. D) Co-culture of acini and macrophages cells for $6 \mathrm{~h}$ at $37^{\circ} \mathrm{C}(\mathrm{n}=3-5)$. Data are illustrative of independent experiments and expressed as means \pm SEM. ${ }^{*} p<0.05$; ${ }^{* *} p<0.01 ;{ }^{* * *} p<0.001$.

Figure S1: Intracellular protease activation and cell death rate in isolated acini. Trypsin and CTSB activation as well as cellular necrosis were not primarily affected by LMP7 depletion. Acini were supramaximal stimulated with CCK and both enzymatic activities assessed with fluorescent substrates in a time-course reaction. Cell death was measured by propidium iodide inclusion. Data are representative of independent experiments and visualized by means \pm SEM. $(n=8-10)$.

Figure S2: Production of pro-inflammatory cytokines in vitro. The corresponding transcripts were assessed by real-time qPCR. 5S and GAPDH were used as housekeeping for acini and macrophages, respectively. A) Isolated acini were incubated with $1 \mu \mathrm{M}$ of $\mathrm{CCK}$ for $6 \mathrm{~h}$ at $37^{\circ} \mathrm{C}$. B) Co-exposed acini macrophages were incubated in cell culture for $9 \mathrm{~h}$ at $37^{\circ} \mathrm{C}$. Secreted levels of IL-6 and IL-1 $\beta$ cytokines were measured in the supernatant by CBA and ELISA, respectively, and IFN- $\beta$ transcript expression by real-time qPCR. Data were normalized respective to the $L M P 7^{+/+} 8 \mathrm{~h}$ group. Data are representative of independent experiments and expressed as means $\pm \operatorname{SEM}(n=3-7)$. ${ }^{*} p<0.05,{ }^{* *} p<0.01$, ${ }^{* * *} p<0.001$.

Figure S3: Absence of LMP7 has no influence on autophagy activation. LC3 isoforms were detected in the pancreas by western blotting analyses. LC3-II ratio to a loading control (ponceau staining) was calculated by densitometry. No differences were observed in the experimental conditions. Data are representative of independent experiments and expressed as means \pm SEM. $(n=10-12)$.

Figure S4: Acinar cell proliferation is unaltered in $\mathrm{LMP}^{-/-}$mice. A) Ki67 proliferation marker was assessed in the pancreas by immunohistochemistry using DAB as substrate (brown-black stain). Hematoxylin accounted for nuclei staining and the positive staining from inflammatory cells was excluded from the quantification. Scale bars, 50 $\mathrm{mm}$. Image representative of five independent experiments. Data are expressed as means \pm SEM. $(n=5-7)$. 
Table 1: Murine primer sequences for the transcripts assessed by quantitative realtime PCR.

\begin{tabular}{|l|l|l|}
\hline Transcript & \multicolumn{2}{|c|}{ Sequences [5'- 3'] } \\
\hline & \multicolumn{2}{|c|}{ reverward } \\
\hline BiP & TGGATAAGAGAGAGGGAGAGAG & CACCACTTCAAAGACACCATTG \\
\hline ATF4 & TCGAATGGATGACCTGGAAAC & AATTGGGTTCACTGTCTGAGG \\
\hline sXBP-1 & TGGAAGAAGAGAACCACAAACT & CATTCCCAAGCGTGTTCTTAAC \\
\hline CXCL-10 & GTGTTGAGATCATTGCCACG & AAGGAGCCCTTTTAGACCTT \\
\hline IFN- $\beta$ & ATCCAAGAGATGCTCCAGAATG & CCAGGAGACGTACAACAATAGTC \\
\hline IL-1 $\beta$ & GAGGACATGAGCACCTTCTTT & GCCTGTAGTGCAGTTGTCTAA \\
\hline IL-6 & CCAGAGTCCTTCAGAGAGATACA & CCTTCTGTGACTCCAGCTTATC \\
\hline LMP7 & ATCGAGATTAACCCTTACCTGC & AGATGCGTTCCCCATTCC \\
\hline 5S & GCCCGATCTCGTCTGATCTC & GCCTACAGCACCCGGTAT TC \\
\hline GAPDH & CCACTCACGGCAAATTCAAC & CTCCACGACATACTCAGCAC \\
\hline
\end{tabular}




\section{Figure 1: Expression of LMP7 subunit in acute pancreatitis}

A) LMP7 protein in pancreatic acini

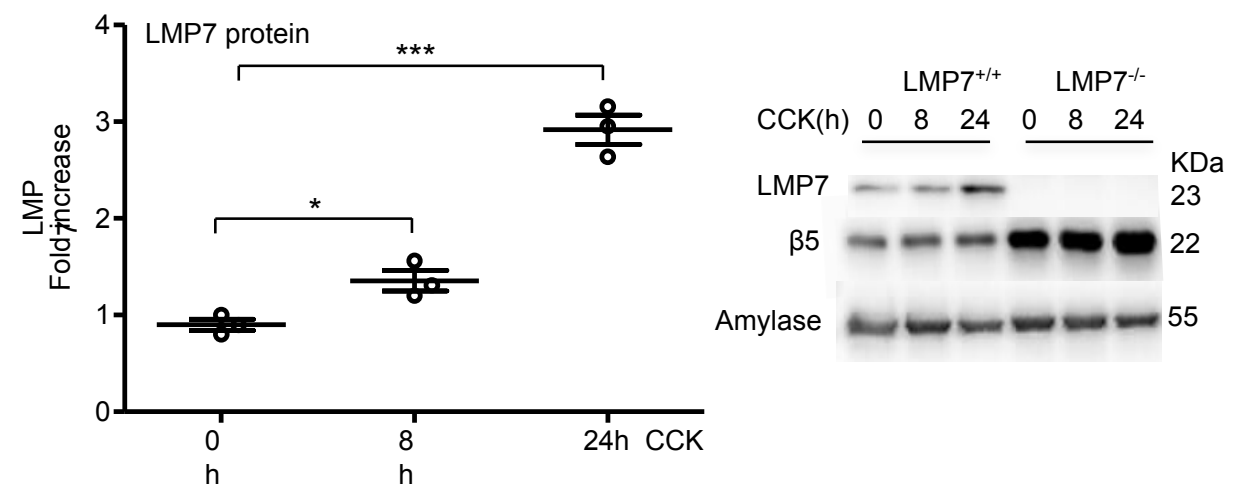

Caerulein-induced acute pancreatitis

B) LMP7 transcript

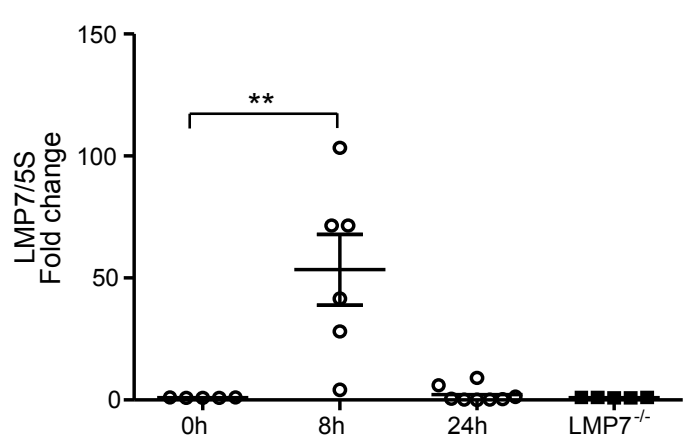

C) LMP7 protein

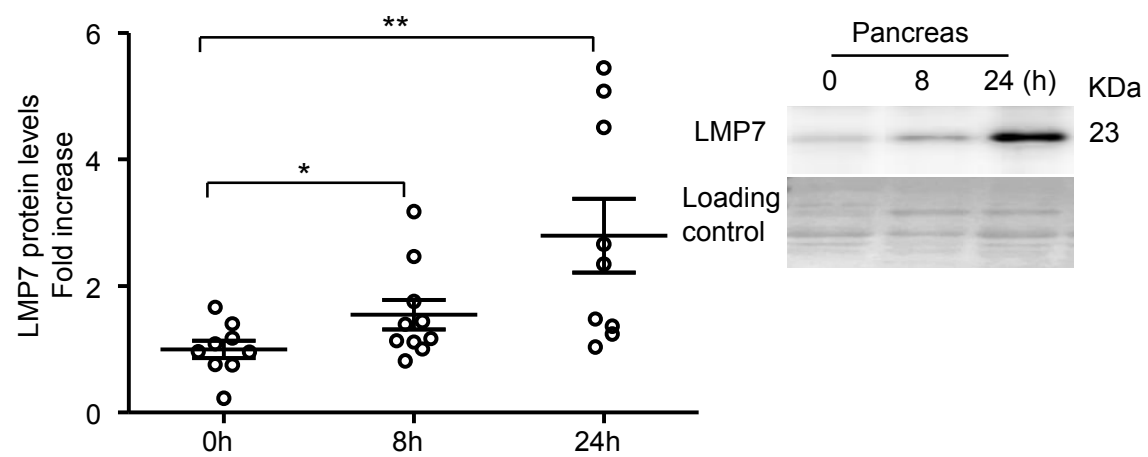


Figure 2: Higher pancreatic damage in the absence of LMP7

A) Serum
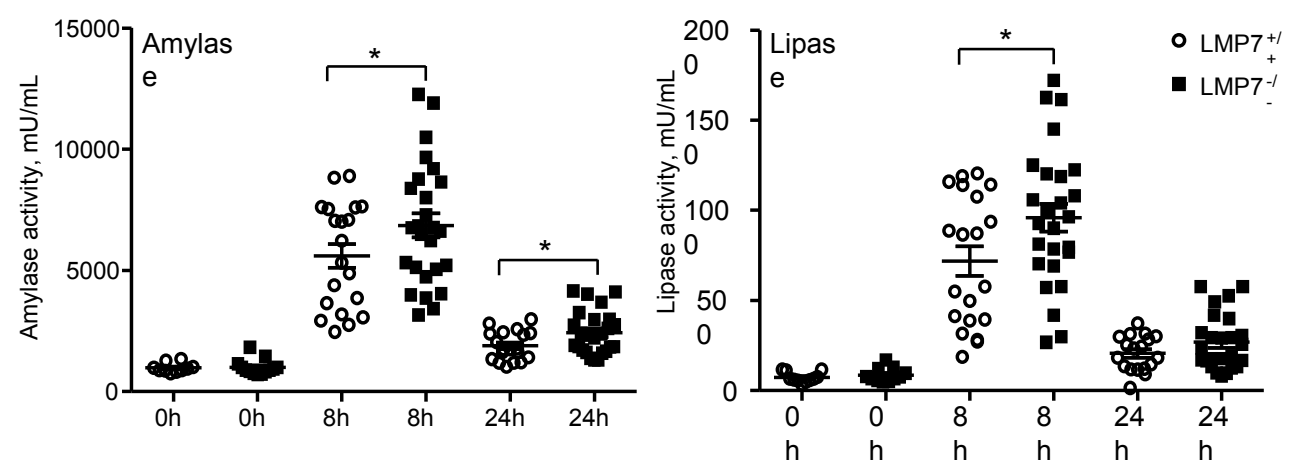

B) Pancreas

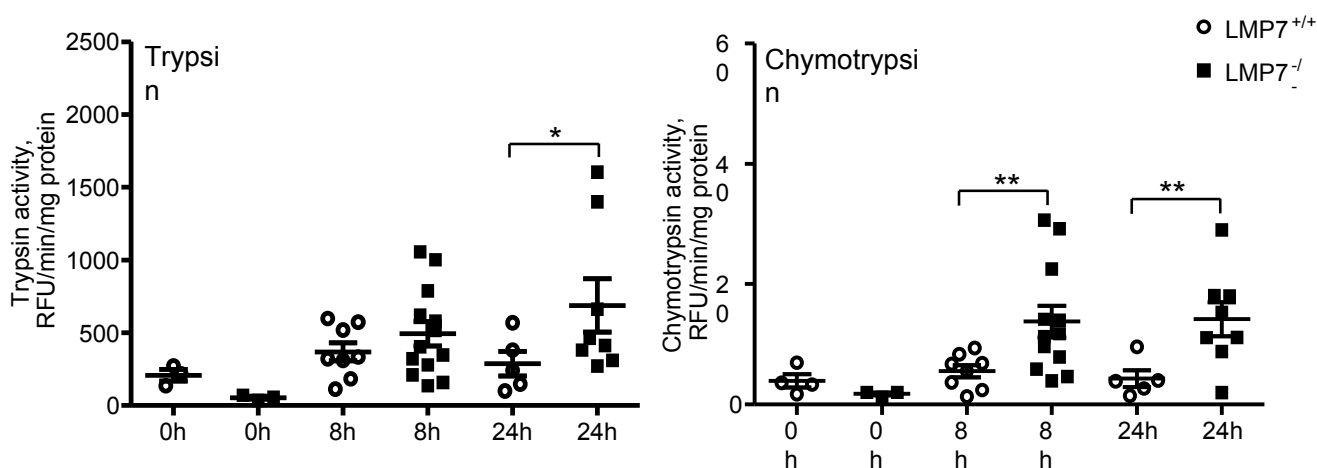

C) Tunel assay
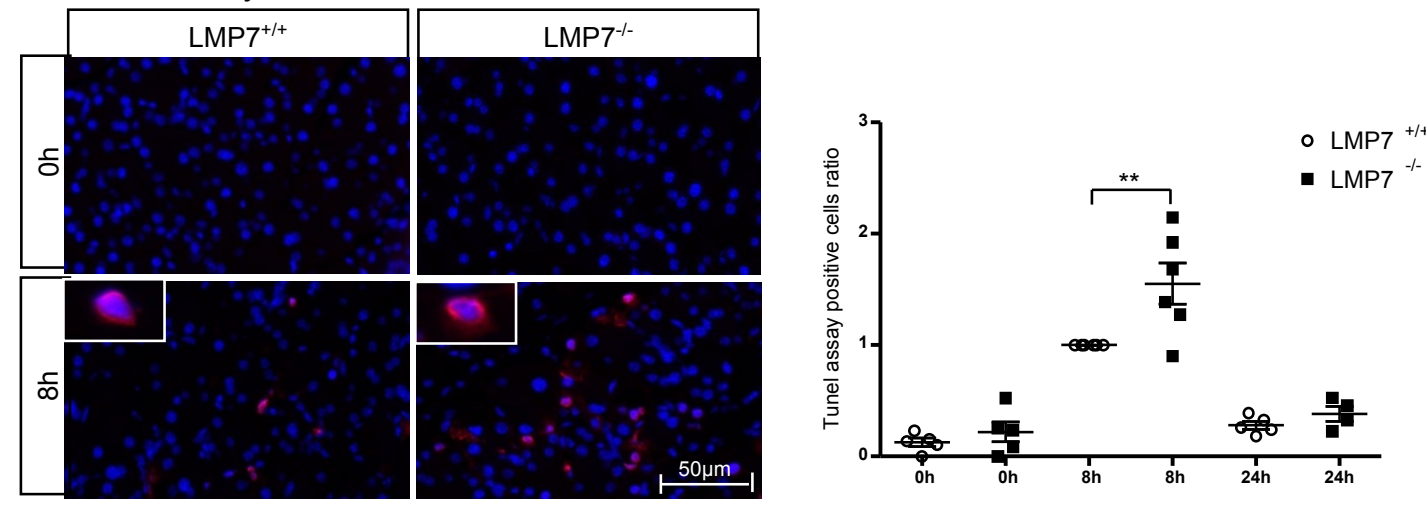

D) Histology of pancreatic damage

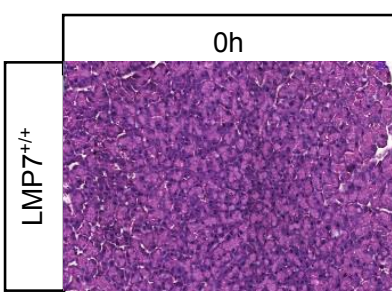

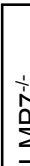

E)

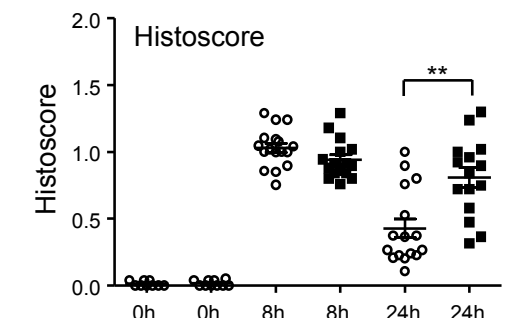

$8 \mathrm{~h}$
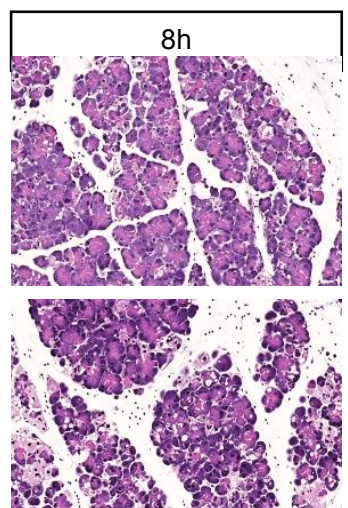
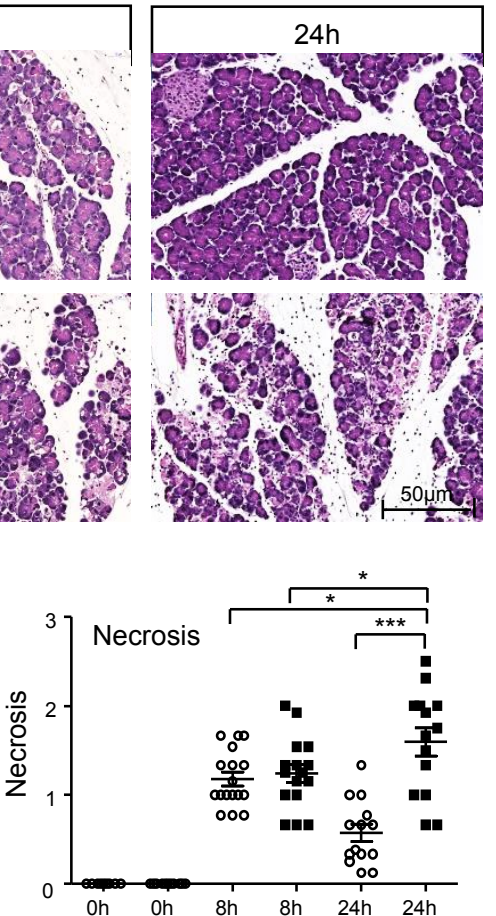
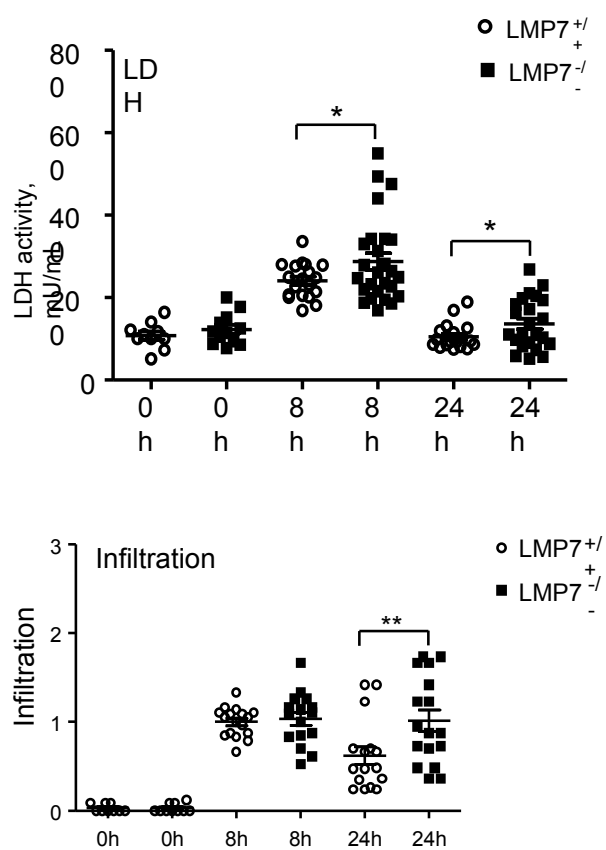

$\mathrm{LMP}^{+/}$

$\mathrm{LMP}^{+-}$ 
Suppl. Figure 1: Intracellular protease activation and cell death rate in living acinar cells.
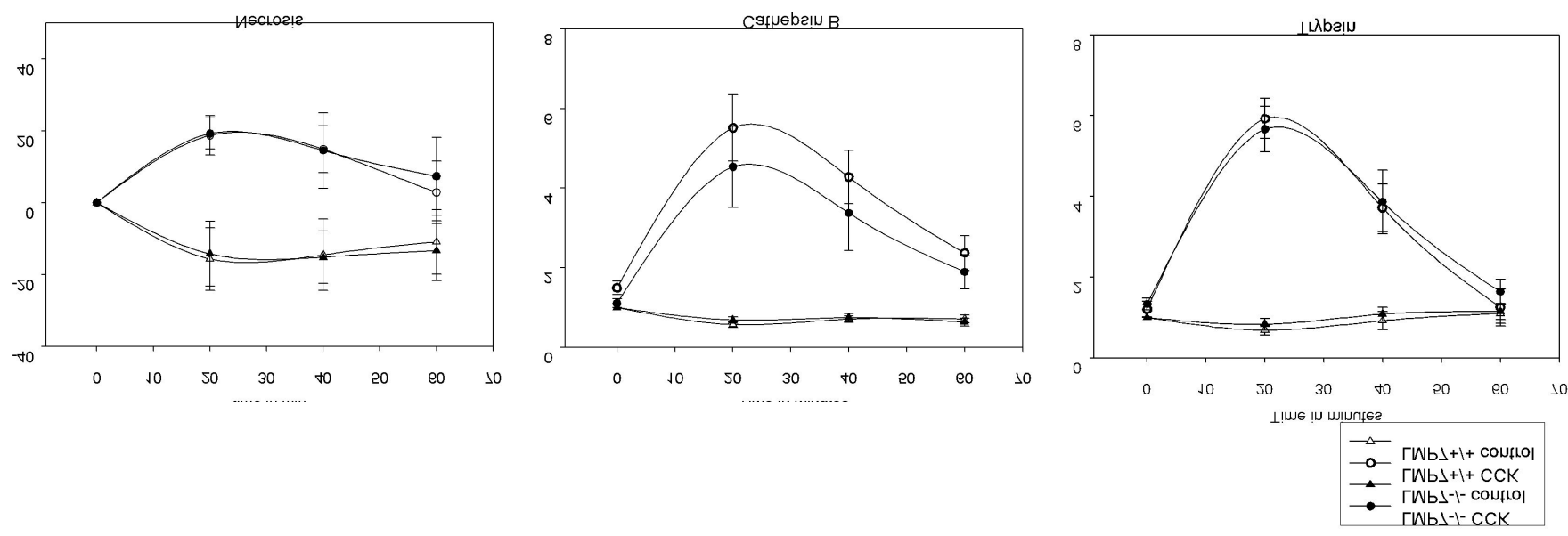
Suppl. Figure 2: Expression and production of pro-inflammatory cytokines in vitro

A) Transcript expression in pancreatic acini
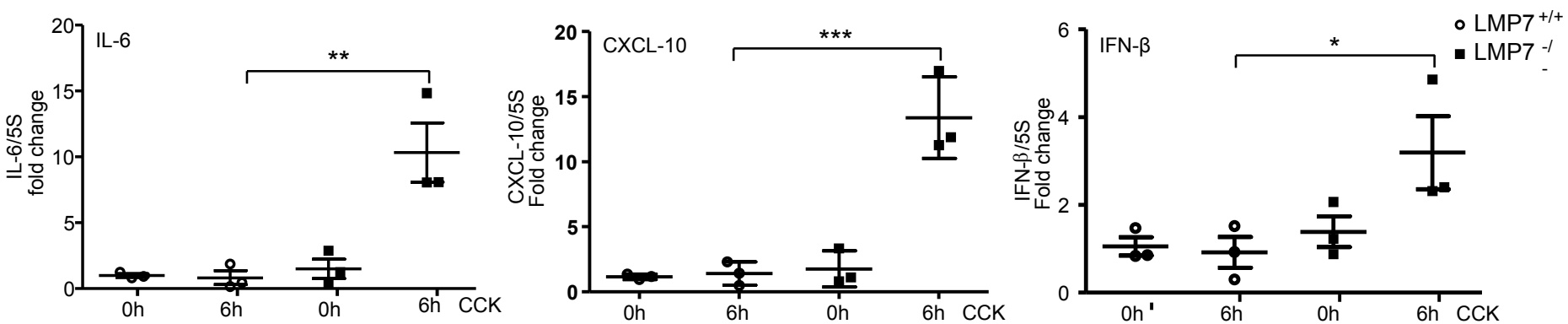

B) IL-6 and IL-1 $\beta$ protein levels and IFN- $\beta$ transcript in co-exposed acini macrophages
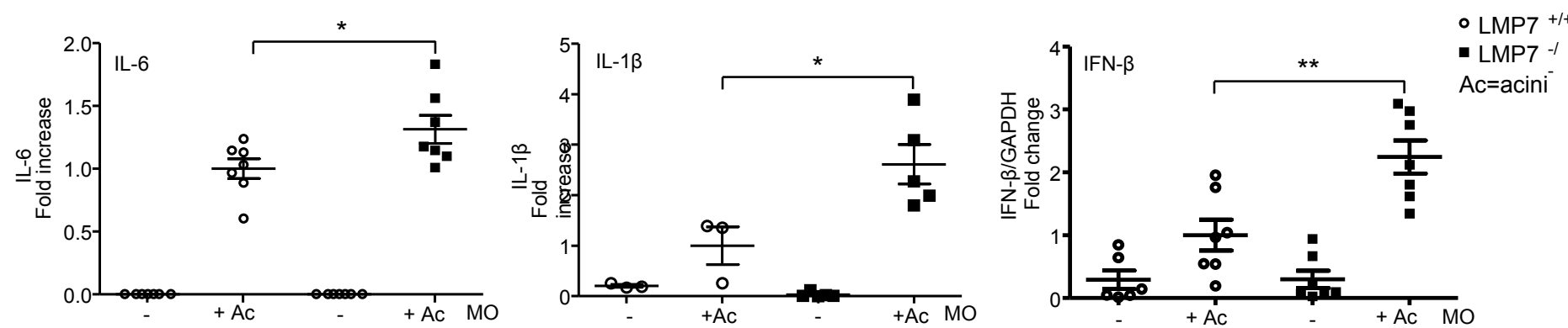
Suppl. Figure 3: Absence of LMP7 subunit has no influence on autophagy activation

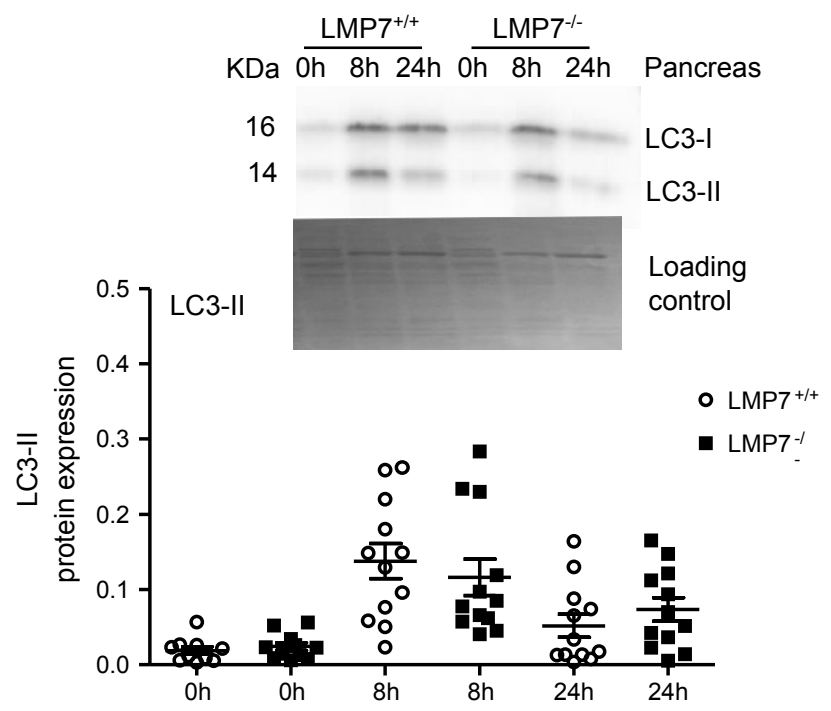


